\title{
So Many Playbills, So Little Time: A Case Study in Fugitive Theatrical Material
}

IN 1936, NOT SO FAR REMOVED from the advent of theatre librarianship, George Freedley wrote that " $[\mathrm{f}]$ or the director of a theatre collection the chief problem is to develop a technique for housing and cataloguing...fugitive material," which he described as "a mass... of indefinite value, irregular size, and often not originally intended for permanent use." Things haven't changed much. Playbills, programs, sheet music, publicity photographs and like material continue to make up a large percentage of patron use at performing arts collections. The issues of irregular size, fragile condition, and quantity continue to make bibliographic control of them elusive.

Multiple articles have addressed access to ephemera in performing arts collections. Freedley's essay was itself a case study of practices at the Theatre Collection of the New York Public Library (now known as the Billy Rose), where each fugitive item was individually cataloged and cross-indexed. That this process was not necessarily feasible at every repository is belied by his handbook's estimates for the number of playbills and programs in the New York Public Library's collection $(125,000)$ and Harvard's $(1,000,000)$. Given such differences in quantity, differences in funding, longstanding historical practices, and the lack of a national or international cataloging standard for ephemera, systems of description have remained largely local for non-book, non-manuscript material.

This isn't to say that nothing has been attempted. In the 1970s, a project among the "Big Ten" universities applied a modified MARC format to performing arts ephemera, with the goal of creating a usable standard compatible among repositories, which might someday facilitate online access. ${ }^{2}$ Such a standard never became reality, and in a prescient article in 1993 Johnson noted users' frustrations with the lack of online records to collocate material from multiple repositories, and called for

1. George Freedley, "Fugitive Material; Its Care and Preservation," in Theatre Collections in Libraries and Museums, An International Handbook, eds. Rosamond Gilder and George Freedley (New York: Theatre Arts Inc., 1936), 148-59.

2. See Louis A. Rachow, "Bibliographic Control" in "Theatre \& Performing Arts Collections," ed. Louis A. Rachow, special issue, Special Collections 1.1 (Fall 1981): 87-97 for an overview of bibliographic projects through 1981. 
"more complete access to, and control over, our collections" through networked catalogs. ${ }^{3}$ Two recent articles have described projects to increase access to theatrical ephemera through cataloging. Stone notes that, while Australian performing arts collections, like their American counterparts, employ multiple systems for access to ephemera, an increasing focus has been placed on access through various online indexes, directories and catalogs. ${ }^{4}$ Davis describes a project at the Mander and Mitchenson Theatre Collection (now part of the University of Bristol), where 6,000 objects were cataloged at the item level using modified MARC records. 2,000 of the objects were then digitized over a 1.5 year period. ${ }^{5}$

Control and access of ephemera in the Harvard Theatre Collection is particularly thorny, given the collection's age, which has allowed for the accrual of voluminous holdings that have been organized in particular (and at times peculiar) ways over a long period of time. Although relatively young, the Harvard Theatre Collection is among the oldest institutional collections of theatrical ephemera in the world. Prior to its inception, such material was not systematically collected and organized by libraries, archives or museums. Those collections might include play texts or secondary sources on performance, but additional documentary evidence lay almost entirely in private collections. ${ }^{6}$ In 1901, George Pierce Baker, instructor of dramatic luminaries such as Eugene O'Neill, laid the groundwork for what would become the Theatre Collection when he encouraged fellow Harvard alumni to purchase a set of contemporary engraved prints of David Garrick and donate them in memory of Justin Winsor, late librarian of Harvard, who had devoted many years of his life to studying the 18th-century British actor and manager. ${ }^{7}$

Over a decade after acquiring the Garrick collection, perhaps the two finest private theatrical collections in America found their way to Harvard. The first was Robert Gould Shaw's (1850-1931), given in 1915, which established the Theatre Collection as an officially named entity and provided for a curator and caretaker to oversee it. The second foundational collection came from the bequest of Shaw's chief

3. Catherine J. Johnson, "Facing the Challenge: Moving Our Theatre Collections into the TwentyFirst Century," Theatre Survey 34.1 (May 1993): 102-109.

4. Richard Stone, "The Show Goes On! Preserving Performing Arts Ephemera, or the Power of the Program," Art Libraries Journal 25.2 (2000): 31-35.

5. Kristy Davis. 2006. "Slipping Thru the Cracks: Issues with Performing Arts Ephemera and A Discussion of the Mander and Mitchenson Theatre Collection." In Performing Arts Collections on the Offensive: $26^{\text {th }}$ SIBMAS Congress, Vienna 2006, 49-56. New York: Lang, 2007.

6. For an overview of the history and organization of performing arts collections in America, in addition to Gilder and Freedley see Laraine Correll, "American Theatre Libraries: Sources of Information," Journal of Library History 7.3 (July 1972): 197-207; Annette Fern, "What Have They Done to the Evidence?" Theatre Survey 45.2 (Nov. 2004): 195-201; and Louis A. Rachow, "Historical Introduction and State of the Art," in Theatre \& Performing Arts Collections, ed. Louis A. Rachow, special issue, Special Collections 1.1 (Fall 1981): 3-11.

7. A history of the first fifty years of the Harvard Theatre Collection can be found in William Van Lennep, "The Harvard Theatre Collection," Harvard Library Bulletin 6.2 (Autumn 1952): 281-301. 
rival, Evert Jansen Wendell. A celebrated collegiate athlete, amateur actor, wealthy man of independent means, and philanthropist, Wendell's collection was massive. Houdini, an avid collector himself, asked a friend if he had heard of "the Drama collector Mr Wendell [sic], here in New York City." "I am told," he wrote, "he has the 'biggest' collection 'ever'." Indeed, the Harvard President's Report in 1918 claims it was the single largest gift the Harvard Libraries had ever received. It was estimated by Van Lennep at 2 million items: 600,000 playbills, 350,000 photographs, 200,000 books, and over 8,000 manuscripts.

The system for arranging this mass of theatrical ephemera was largely inherited from Shaw, perhaps not surprising as he was appointed its first curator with his gift. Van Lennep describes Shaw's pioneering efforts:

"Since four-fifth of the Collection consisted of ephemera-thousands of playbills, programs, posters, prints, photographs, pamphlets, broadsides, sheet music, letters, documents, clippings - the job of setting up the Collection must have been a laborious and difficult one, and Shaw... could turn to no one for advice, because his was the first of its kind in this country. It is a tribute to his wisdom that the methods of arrangement he worked out with his assistant, Mrs. [Lillian Arvilla] Hall, have proved on the whole so practical that few changes have had to be made to them.",

Due to sheer volume, the majority was arranged but not described, and filed into multiple series with various organizing principles. The arrangement was first by format, then further subdivided based on whatever category the curatorial staff felt would be most useful for researchers. For instance, playbills and programs were divided by geographic location, such as London, New York City, or Boston. These geographic subdivisions each constituted separate series, and were organized by theater, then date. To give a sense of scale, the Boston playbills and programs today constitute 352 linear feet. Although the Theatre Collection takes pride in local holdings, the size of this series isn't a provincial aberration. London playbills constitute 236 linear feet, and the New York City series of playbills consists of 450 linear feet.

The basic system of organization remained unchanged over time, though the number of series proliferated over the years. For instance, to more easily serve patrons researching notable performers, a series of "star playbills" was created using duplicate items from existing series. Similarly, to facilitate patrons researching amateur

8. Harry Houdini to Quincy Kilby, undated, from scrapbook assembled by Quincy Kilby, fTS 563.39.13, Harvard Theatre Collection, Houghton Library, Harvard University.

9. Van Lennep, “The Harvard Theatre Collection," 283. 
productions, related programs were separated to create new series. Later they were further subdivided, with churches, schools, and colleges each receiving their own series. This practice led to a proliferation of new series, a total of 55 for programs alone, and close to 120 total for all formats, ranging in size from a single item to hundreds of thousands of items.

Sheer size remains a primary obstacle to cataloging the series, and the Theatre Collection has been unable to keep up with sorting and filing the large volume of ephemera taken in each year. As a result, there are currently 998 linear feet that have remained unprocessed for 20 years or more, essentially inaccessible. This is in addition to the bulk of material, which is physically arranged but has no cataloging description, and is therefore only discoverable by staff mediation.

Given the immense size, it should be evident why it remains impractical to individually describe each item. But this presents a problem for discovery and accessnamely, that there is no bibliographic description for users to discover on their own. Traditionally, this has been solved by having the process entirely mediated by reference staff. Users arrived, preferably by appointment, and explained their project. Staff then described how the arranged series were generally organized, and solicited relevant search terms from users, such as names of people, or production titles and dates - essentially a mandatory reference interview. Staff then delved into the stacks, physically searching among the various arranged series, and either reappeared with the desired item or told the user that it was not among the holdings. Further complicating the matter, many arranged series contain items of various sizes, each housed in different parts of the stacks, for which staff must conduct an exhaustive search.

A well-trained and dogged librarian can accomplish the task, but there are several downsides. Foremost is that due to lack of any description there is no way for users or staff to discover what is in the arranged series without physically searching for it. This renders remote discoverability effectively nonexistent. Users might call or e-mail staff to get a sense of how much material concerning a particular subject is in the collection, but limited time and resources mean that staff cannot search for more than a few queries per remote user. Moreover, staff are simply not as efficient at physically searching and retrieving material as a machine discovery system is at searching and retrieving stored metadata. This hampers not only off-site researchers, but on-site researchers as well, who might better use their limited time by searching descriptions of a potentially larger portion of the collection described in the catalog, rather than waiting for staff to physically search the smaller amount that is currently organized. 
Further, to function properly, this system requires a highly knowledgeable staff. Of course, all special collections librarians should know their collections well. But when a significant portion of the collection is uncataloged, a certain level of esoteric knowledge is essential. Collection information is almost entirely stored in the memories of a few human beings rather than in a system designed for bibliographic description. It might take many months for an employee to become comfortable in answering even basic queries with a sense of certainty, making staff turnover much more problematic.

With the financial downturn of 2008 and its aftermath came multiple staff retirements and the closing of the Theatre Collection reading room. Incorporating access to the Theatre Collection into the Houghton Library reading room had the upside of increasing the number of hours the collection was available for research. But these increased hours, combined with the decreased staff, meant that a librarian specializing in the Theatre Collection would not be available at all times the reading room was open. The library considered keeping access to the collection restricted to certain hours, or requiring an appointment for its use. Both of these options seemed undesirable, particularly given the trend in the profession of increasing both physical and remote access to collections.

In order to properly serve Theatre Collection researchers, additional reference staff needed to be trained in the collection, which meant that knowledge would need to become easier to transmit. Houghton stacks staff also needed to incorporate retrieval of Theatre Collection material into the rest of their duties, meaning material had to be easier to locate. For these reasons, it was now imperative to have bibliographic control of the series.

A cross-departmental team formed to address the issue in 2009. The group decided on a small size in an effort to be agile, consulting with other knowledgeable staff frequently when needed. First, the team surveyed the arranged series, capturing the format of each, as well as its organizing principle, physical location and extent. The survey revealed 4,159 linear feet split across ca. 120 series. The team used the survey data, along with the reference staff's experience in how items are used by researchers, to determine how material should be organized going forward.

The first decision made was to close all of the current arranged series to new material. They had simply grown too baroque to reasonably manage in future workflows of intake and cataloging. Duplicative series, such as the multiple series of amateur theatrical programs mentioned above, were merged when practical in order to limit repetition. This reduced the number of existing series to 93 . 
In addition to closing existing series, a minimal number of new series were created for cataloging of existing unprocessed ephemera as well as future acquisitions. Rather than physically arranging this material based on any intellectual principle, each item will be given an accession number, and filed by it. Intellectual organization will take place solely in description via MARC records and online finding aids, eliminating both the problems of continual physical arrangement and lack of description.

Next, focus turned to classification. Because series were mostly divided by format and organizing principle, rather than by subject, it was necessary to structure their classification by format rather than use a subject classification system. Formats were grouped together, then each series given a number in consecutive order. These call numbers would provide the basis from which to create collection level records. Initially, basic MARC records were created for each series. These records included title, current extent, a summary description, and several subject headings and genre terms. The information was purposely basic, as the team decided on an iterative approach in order to avoid getting bogged down in "perfect" access to a small portion of the collection to the detriment of the majority.

However, more detailed descriptions for the closed series will need to be created to allow for better online discovery. Because users in performing arts collections generally frame their research questions in terms of a title, name, or subject, rather than by a format, more itemized and detailed descriptions would be necessary for effective online searching. For example, users do not generally search for a collection of playbills of a city's theatres, but for a specific theatre, or a specific title. Subject headings in the MARC records give some detail (prominent theatres in a series, e.g.) and increase the visibility of the series, but not at a level sufficient for most research projects. More exact descriptions are also important for staff. They will allow curators to have an overview of their holdings more easily, and cause a decrease in "fishing trips" by stacks staff, who without them spend ten or fifteen minutes looking for an item that might not exist.

The team defined the necessary requirements for a system of access and discovery as being accessible to users online, cost feasible, and part of a standards compliant system that would continue to be supported by the university for the foreseeable future. Three options were examined: TEmpleted Database (TED), a Harvard Library administered XML database system for non-standard collection material; a mass digitization project, combined with OCR; and EAD encoded finding aids. While promising, the team felt that the TED system would not be as easily discoverable from the open web as the other options. It would also be a separate standalone interface from other current discovery tools used by the collection, increas- 
ing the number of places a user would need to search. The cost of digitizing and generating OCR for every piece of ephemera is not currently cost feasible. Aside from sheer scale, most playbills would need to undergo preservation treatment. Additionally, many playbills contain a number of fonts not easily recognizable by existing OCR software, necessitating more human intervention in expanding the software's recognition and ensuring quality control. EAD finding aids provide the ability for ample description and open web access, and are currently used for archival collections in the Theatre Collection, but they do not provide the visual frame of reference for photographs and visual prints.

The team decided to implement two basic approaches. Visual material in the public domain would be scanned and deposited in the University digital repository service, and made accessible through Harvard's Visual Information Access database (VIA). ${ }^{10}$ The team focused on a series of cabinet card portraits as a test case for this approach. A basic Excel template was created with columns for subject, format, date, photographer, call number, image file name (created by formula and based on call number), and notes (inscriptions, provenance and other information that might be written on the back of the cabinet card). The library's administrative assistant enters the information for a batch of photographs in the spreadsheet when she has downtime in her schedule. The spreadsheet is then reviewed by an archivist, and the cabinet cards and spreadsheet are delivered to the library's imaging services department. At this point the cabinet cards are digitized and the images, along with the metadata from the spreadsheet, are entered into VIA.

The second approach the team decided on was for material primarily non-visual in nature. This material would be described through EAD encoded finding aids. The team focused on the existing series of playbills and programs from Boston theatres as its test project for this approach. The goal was to create a finding aid in a relatively fast and simplified way, so that the method could be applied across multiple series. The team decided to keep the order of the series intact, rather than attempting to reorganize it-a time consuming task for 352 linear feet. Entries were thus organized by theatre, and would include the date ranges of each theatre's holdings and physical extent. While a more detailed description (e.g. including performance titles) would be beneficial to users, it is time prohibitive at this point. Since the collection was already arranged alphabetically by theatre, the assumption was that it would not require much processing. Unfortunately, both alphabetization and housing of the series was less than perfect, and a significant amount of time was spent inventorying and improving the physical arrangement of the material.

10. The Visual Information Access database is available at http://via.harvard.edu 
After arrangement, reference and technical services staff worked together to inventory the series, again in an Excel spreadsheet template provided by an archivist. The information captured included: item number, size, theatre name, dates, extent, theatre location, and any notes, including see-also references. The inventory information was entered by reference staff, as time permitted between other duties, into the spreadsheet. When completed, the spreadsheet was converted to XML, which was then edited by the archivist, who did some cleaning and standardization of data, and provided the front matter to the finding aid.

Numerous physical locations made it undesirable to follow the usual cataloging convention at Houghton of separating entries for oversized material from standardsized material. To do so would potentially separate playbills for one theatre across 6 different alphabetical sequences within the finding aid, a prospect confusing for users. However, stacks staff desired to have the identifying numbers for each entry remain consecutive within a size designation in order to facilitate retrieval. To accomplish this, the finding aid would be intellectually organized as one consecutive $A-Z$ list of theatres, and each entry would include the size designation and a number that corresponded to its placement on the shelf. The example below demonstrates the approach:

- (20) Boston Bijou Theatre : playbills and programs, 1882-1907 and undated. 1 box. Theater location: West side of Washington Street.

- $\quad$ bpf (204) Boston Bijou Theatre : playbills and programs, 1883-1901. 7 folders. Theater location: West side of Washington Street. See also: Bijou Opera House. ${ }^{11}$

Assessment of this first case, as well as the overall plans for the arranged series, is ongoing. From a technical services standpoint, the results have been positive. Generating MARC records for all of the series finally achieved basic bibliographic control over the collection. The playbill test case has proven that a basic level of online description could be produced efficiently and relatively quickly within the established workflows of the library. Work has since proceeded on the London playbills, with plans to catalog the New York City playbills afterward.

Work has also begun on existing unprocessed and newly acquired ephemera. An archivist has created MARC records for the new series, and in the coming year she will begin populating finding aids for program series. Some of the new photographic series have already been cataloged and digitized, and are accessible in VIA.

11. The full finding aid can be found online at http://nrs.harvard.edu/urn-3:FHCL. Hough:hou02431. 
It is hoped that using these new workflows, staff will be able to keep up with the addition of new ephemera and not create or add to the backlog of unprocessed material.

Results have been more mixed from a public services perspective. Some users have been grateful for the increased transparency, and the finding aid of Boston playbills and programs has been near universally welcomed and understood. However, as few of the other series currently have anything but very basic descriptive information, and as the number of series is so large, it is difficult for patrons to know where to begin their search. Reference staff created an online guide for navigating the series, which has mitigated the confusion somewhat. Reference interviews are more helpful, though they are not automatically triggered in the same way as when the discovery process was completely mediated by a Theatre Collection specialist in a separate reading room. As it stands, there is still some confusion over the series, and most likely there will continue to be until more robust descriptions exist. Luckily, that work continues to move forward, and combined with an effort for redesigned bibliographic instruction and outreach, we anticipate it will make the collection more accessible in time.

But with all our measurable successes in organizing and cataloging the fugitive material to this point, the most gratifying success has been the staff from the various departments coming together and working on this enormous and complicated project. Technical services staff feel a real commitment and ownership for the state of the collection and how findable and accessible it is to researchers. Many public services staff members now have a deeper understanding of the complexities involved in processing and describing collections, after having done so themselves. Curatorial staff are more informed about cataloging and reference implications when making collections decisions. In short, all departments now understand the challenges the others face. 